\title{
Influence of Family Dynamics on Medication Adherence among Hypertensive Patients in a Tertiary Hospital in South-West Nigeria
}

\author{
Authors \\ Olusegun Emmanuel Gabriel ${ }^{1}$, Oluwaserimi Adewumi Ajetunmobi ${ }^{1}$, \\ Olabode Muftau Shabi ${ }^{1}$, Adebara Idowu Oluwaseyi ${ }^{2}$, \\ Olusegun Adesola Busari. ${ }^{3}$, Ayokunle Samuel Dada ${ }^{4}$ \\ ${ }^{1}$ Department of Family Medicine, Federal Teaching Hospital Ido-Ekiti, Ekiti state Nigeria \\ ${ }^{2}$ Department of Obstetrics and Gynaecology, Federal Teaching Hospital Ido-Ekiti, Ekiti state Nigeria \\ ${ }^{3}$ Department of Medicine, Cardiology unit, Federal Teaching Hospital, Ido-Ekiti, Ekiti State \\ ${ }^{4}$ Department of Medicine, Ekiti State University Teaching Hospital, Ado-Ekiti \\ Corresponding Author \\ Olusegun Emmanuel Gabriel \\ Department of Family Medicine, Federal Teaching Hospital Ido Ekiti, Ekiti state Nigeria \\ Email:layodeg@gmail.com,08068886933
}

\section{INTRODUCTION}

Hypertension is an overwhelming global challenge estimated to cause 7.5 million death, which is about $12.8 \%$ of all deaths. ${ }^{1}$ The emerging pandemic of non-communicable diseases (NCDs) is creating major health challenges worldwide. Of the 56 million global deaths in 2012, 38 million $(68 \%)$ were attributed to NCDs, with almost three quarters $(74 \%)$ of these deaths occurring in low and middle income countries. ${ }^{2}$ Indeed, it is estimated that up to three-quarters of the world's hypertensive population will be in economically developing countries by the year 2025. ${ }^{3,4}$ Nigeria, like most other developing countries is undergoing epidemiological transition and faces the double burden of communicable and noncommunicable diseases. $^{3,4}$ Of the latter, hypertension is one of the most important treatable causes of morbidity and mortality ${ }^{3}$.
It is documented that uncontrolled blood pressure increases the risk of ischemic heart disease 3-to 4fold, ${ }^{5}$, and the overall cardiovascular risk by 2 -to 3-fold. ${ }^{1}$ The incidence of stroke increases approximately 3 -fold in patients with borderline hypertension and approximately 8 -fold in those with definite hypertension. ${ }^{1}$ These will invariable have negative impact on the family. The reported prevalence of hypertension varied around the world, with the lowest prevalence in rural India (3.4\% in men and $6.8 \%$ in women) and the highest prevalence in Poland $(68.9 \%$ in men and $72.5 \%$ in women). ${ }^{6}$ while the overall prevalence of hypertension in Nigeria ranges from $8 \%-46.4 \%$ 7-9 Studies worldwide, including many from Nigeria indicates that despite the availability of safe and effective medical therapy, over half of all hypertensive patients do not take any treatment and more than half of those on treatment have blood pressure over the $140 / 90 \mathrm{mmHg}$ threshold. ${ }^{8,9}$ 
Good blood pressure control is important in the management of hypertension and prevention of complications. Good control however depends on dietary and life style modification; and proper adherence to medication. Family dynamics are key factors in influencing the aforementioned. This review on family dynamics and blood pressure control in hypertensive was performed from a Family Medicine perspective, which defines the patient's condition within the context of the people-oriented nurturing environment from which the patient emerged.

The family remains the most basic relational unit and the most intimate social environment in our society. ${ }^{10}$ Numerous definitions abound, and vary from a group of intimates with a history and a future, to a nuclear family with father and/or mother and progeny, to all people living under the same roof and sharing physical or economic arrangements. ${ }^{10}$ Therefore, the primary function of family which is provision of nurturance and support for psychosocial growth and development of its member is paramount to successful treatment of hypertension.

The family is the unit of care; it has great importance in effective management of diseases. It influences the causation of acute diseases and has a great impact on the rehabilitation of chronic disease patients. The family unit determines therapeutic success or failure (including medication adherence); it determines the degree of mental health and illness of its members and plays a critical role in preventive and wellness aspect of health care ${ }^{10,11}$

To consider the family as a unit of care requires the Family Physician to look at the family dynamics as part of the causation of illness in the person or facilitating care. The family as a group generates, prevents, tolerates or corrects health problems within its membership.

The family is the most frequent source of decision making about health and personal care for minor illness, long-term illness, pre- and post-hospital care. It is most often the family unit, not the individuals or the health professionals, that decides whether the individual should seek or use healthcare or not. ${ }^{10}$ The family is a primary health referring and referral source, and the cooperation of the family is often necessary in fulfilling medical treatment prescribed by a physician. ${ }^{10,11}$

\section{Objective}

To determine the influence of family dynamics in medication adherence among hypertensive patients in Federal Teaching Hospital, Ido-Ekiti.

\section{MATERIAL AND METHOD}

This was a descriptive cross-sectional hospital based study of the influence of family dynamics on adherence to antihypertensive therapy in hypertensive patients attending the general outpatient clinic of Federal Teaching Hospital (FTH), Ido-Ekiti, Ekiti State, in the south-west Nigeria. Hypertensive clinics run five days in a week in the clinic. The tertiary health institution is situated in a semi-urban settlement of Ido-Ekiti, for easy access of a large number of people from all over Ekiti State and its environs. The study was conducted over a period of four months.

Consenting ambulatory hypertensive patients of age 18 years and above who have been receiving prescribed antihypertensive medications at FTHI for at least a period of three months as at the time of the study were included. Pregnant patients were exluded (due to haemodynamic changes of pregnancy).

Sample size was determined using the formula: $\mathrm{N}=\mathrm{Z}^{2} \mathrm{P} \mathrm{Q} / \mathrm{D}^{2}$ Where $\mathrm{N}=$ Sample size, $\mathrm{Z}=$ Level of confidence (the standard normal deviate set at 1.96, which corresponds to the $95 \%$ confidence level. $\mathrm{P}=$ Prevalence (The proportion in the target population estimated to have a particular characteristic). Prevalence rate of $41.5 \%$ by Osamor PE et. al was used. This was a prevalence rate of poor adherence to antihypertensive therapy got in their study in that was conducted in the Idikan community, Ibadan, a city in the southwestern Nigeria, as part of a larger community-based study of the sociological aspects of hypertension. $^{12} \mathrm{Q}=1-\mathrm{P}, \mathrm{D}=$ Degree of 
accuracy desired, set at 0.05 , Therefore, $\mathrm{n}=$ $(1.96)^{2}(0.415)(0.585) / 0.05^{2}=373$. This was the minimum sample size. To cater for attrition assuming anticipated response was $90 \%$, then $\mathrm{n}$ $=373 / 0.9=415$, which was rounded up to 420 . Sample size of 420 was used for this study.

Systematic random sampling method was used to recruit the participants. Every second consenting patient was selected after selecting the first patient from two participants of the day through simple random sampling by picking yes or no on two folded pieces of paper. The consenting patient who chose yes served as the first sample for the day.

The participants were recruited after written consent was taken, as they came for their routine medical check-up. The data collection tool was by:

1). A semi-structured interviewer administered questionnaire:-The questionnaire was pilot-tested on 20 patients out of the study centre who were not included in the final study sample and proper adjustment was made. The questionnaire enquired information regarding patient sociodemographics, family dynamics and Information was extracted from patients' case notes on their prescribed drugs, dosages and their remaining pills were counted. To further increase the strength and consistency of the results, an adherence assessment tool- the 8-items Morisky Medication Adherence Scale (MMAS) ${ }^{13}$ was included. Those who scored $80 \%$ in both measures were considered as having good adherence.

2). Perceived Social Support-Family Scale ${ }^{14}$ (PSS$\mathrm{Fa}$ ) was used to assess the level of family and social support the patients had. PSS-Fa is a 20item validated measure of social support. Perceived family support is the degree to which one perceives how his or her needs for support are fulfilled by family. Subjects would respond "yes", "no", or "don't know", with each "yes" answer scoring +1 . Any other response was scored zero. Items $2,6,7,15,18$, and 20 in the questionnaire are reversely scored (a "no" response was scored as +1$)$. Summated scores were used to arrive at a family support score. Possible ranges of scores were 0-20. Higher scores indicated higher level of perceived family support. (Scores equal to or greater than 11 points suggest strong family support, scores $7-10$ points suggest weak family support while scores equal or less than 6 points suggest no family support). The Perceived Social Support- Family Scale has been found to have good reliability and validity. ${ }^{14}$ The original Perceived Social Support Scale has an alpha coefficient of 0.90 indicating that the scale has excellent internal consistency. The alpha for the PSS-Fa ranged from 0.88 to $0.91 .^{14}$ The instrument was translated into Yoruba by a Yoruba-speaking linguistic professional who is experienced in health surveys. Precise idiomatic equivalents were employed as much as possible

3) Blood pressure (BP) was measured twice, by the hospital staff nurse and the authors using mercury sphygmomanometers and stethoscopes. The patients were allowed to sit for 5-10 minutes before measuring BP A cuff with bladder that was $12-13 \mathrm{~cm} \times 35 \mathrm{~cm}$ and a larger one for fat arms was used at the upper two-third (2/3) of the arm. First appearance of sound was used for systolic and a phase 5 Korotkoff sound (disappearance of sound) was used to measure diastolic blood pressure (BP). The BP was measured in standing position in elderly subjects (greater than 65years) and diabetic patients to assess autonomic nervous system integrity. Sphygmomanometer cuff was placed at heart level in the sitting and standing position of the patient. Blood pressure controls over the last two or three previous visits was checked in their case notes and documented.

Adherence percentage was determined using the formula. $^{15}$

No. of pills prescribed - No. of pills missed ${ }^{*}$ X 100 No. of pills prescribed

*Number of pills prescribed/missed was calculated for four weeks of medication. Intake of $80 \%$ of the prescribed medication was taken as good adherence. 
The data was analyzed using the Statistical Package for Social Sciences (SPSS) version 18. Discrete variables were presented using appropriate tables and charts. Test of significance was done using chi-square $\left(\chi^{2}\right)$ and t-test as appropriate. P-value was set at $95 \%$ confidence level.

Ethical Clearance was obtained from the Hospital's Ethical and Research Committee and written informed consent of each subject was obtained.

\section{RESULT}

SOCIODEMOGRAPHICS AND FAMILY DYNAMICS OF THE RESPONDENTS

A total of four hundred and twenty (420) hypertensive subjects attending Federal Teaching
Hospital Ido-Ekiti were studied. Mean age of the respondents was $60.67 \pm 13.85$ years.

Table 1 shows the age and gender distribution of study subjects. Three hundred and seven subjects representing $73.1 \%$ were 51years and above. One hundred and fifty-one males (36.0\%) and 269 $(64.0 \%)$ females participated in the study, giving a male to female ratio was $1: 1.8$.

Table 1: Age and Gender Distribution of the subjects

\begin{tabular}{lccc}
\hline Age group (years) & $\begin{array}{l}\text { Male } \\
\mathbf{n}(\%)\end{array}$ & $\begin{array}{c}\text { Female } \\
\mathbf{n}(\%)\end{array}$ & $\begin{array}{c}\text { T otal } \\
\mathbf{n}(\%)\end{array}$ \\
\hline $31-40$ & $4(2.6)$ & $17(6.3)$ & $21(5.0)$ \\
$41-50$ & $29(19.2)$ & $63(23.4)$ & $92(21.9)$ \\
$51-60$ & $17(11.3)$ & $97(36.1)$ & $114(27.1)$ \\
$61-70$ & $46(30.5)$ & $46(17.1)$ & $92(21.9)$ \\
$71-80$ & $34(22.5)$ & $29(10.8)$ & $63(15.0)$ \\
$81-90$ & $13(8.6)$ & $17(6.3)$ & $30(7.1)$ \\
$91-100$ & $8(5.3)$ & $0(0)$ & $8(2.0)$ \\
\hline Total & & & $420(100.0)$
\end{tabular}

Table 2 below shows the Socio-demographic characteristics of the respondents. Many (37.9\%) had only primary education and a larger proportion of participants belong to social class IV (49.0\%).

Table 2. Socio-demographic Characteristics

\begin{tabular}{lc}
\hline Characteristics & No (\%) \\
\hline Education & \\
Tertiary & $93(22.1)$ \\
Secondary & $84(20.0)$ \\
Primary & $159(37.9)$ \\
No education & $84(20.0)$ \\
Social class & \\
Class I & $13(3.1)$ \\
Class II & $80(19.0)$ \\
Class III & $75(17.9)$ \\
Class IV & $206(49.0)$ \\
Class V & $46(11.0)$ \\
Place of domicile & \\
Within Ido-Ekiti town & $88(21.0)$ \\
Outside Ido-Ekiti & $332(79.0)$ \\
Ethnic group & $412(98.2)$ \\
Yoruba & $4(0.9)$ \\
Ibo & - \\
Hausa & $4(0.9)$ \\
Others & \\
Religion & \\
Christianity & $382(91.0)$ \\
Islam & $38(9.0)$ \\
Others & - \\
\hline
\end{tabular}


In table 3, Family dynamics of the respondents showed that $290(69.0 \%)$ of the respondents were married and were still with their husband, only 12 (3.0\%) subjects were single and $109(26.0 \%)$ were widows. Two hundred and thirty one $(55.0 \%)$ were in monogamous marriage, 177 (42.0\%) were polygamy. Majority, 240 (57.1\%), had 7 or more members in the family. Two hundred and seventy five subjects $(65.5 \%)$ had their monthly family income greater than the minimum monthly salary wage in Nigeria. Two hundred and eighty one subjects $(66.9 \%)$ had good family support while 139 (33.1) had poor family support (weak and no family support).

Fig 3: Family dynamics

\begin{tabular}{lc}
\hline Characteristics & n (\%) \\
\hline Marital status & \\
Single & $12(3.0)$ \\
Married & $290(69.0)$ \\
Widowed & $106(25.0)$ \\
Separated & $8(2.0)$ \\
Divorced & $4(1.0)$ \\
Type of Marriage & \\
Single & $12(3.0)$ \\
Monogamy & $231(55.0)$ \\
Polygamy & $177(42.0)$ \\
Family size & \\
2-6 members & $176(41.9)$ \\
$\quad$ 7 members & $240(57.1)$ \\
Family level income /month & \\
$\quad=18,000$ & $145(34.5)$ \\
$>18,000$ & $275(65.5)$ \\
Family Support (PSS-Fa) Rating & \\
Strong family support & $281(66.9)$ \\
Weak family support & $139(33.1)$
\end{tabular}

\section{LEVEL OF BLOOD PRESSURE CONTROL}

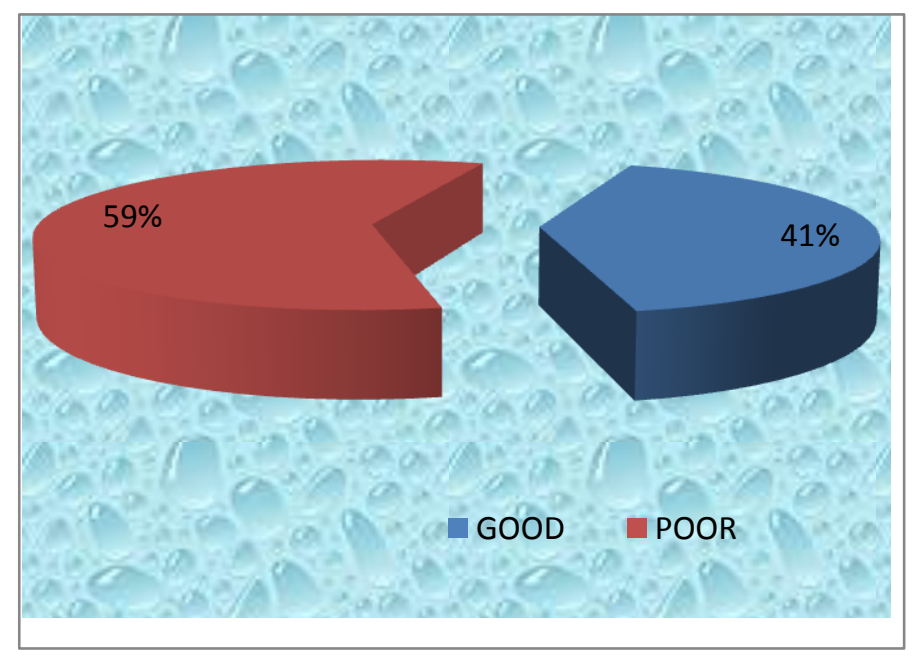

Figure 1: Level of Blood Pressure Control
Blood pressure control and adherence to medications are as shown in figures 1 and 2. One hundred and seventy two (41.0\%) of the study subjects has good blood pressure control while 248 subjects $(59.0 \%)$ did not have their blood pressure controlled below 140/90mmHg.

Relationship of family dynamics and adherence to treatment is documented in table 4, marital status, type of marriage, family size were significant factors for adherence to antihypertensive drugs ( $p$ $<0.05$ ), monogamy was a significant factor for adherence to antihypertensive $\operatorname{drugs}(\mathrm{p}=0.000)$, having a family size between 2-6 gave a significantly better adherence to medication than being single or having more than 6 family members $(\mathrm{p}=0.016)$.

Those who earn a fix income monthly, (either less than or more than 18,000 naira) had a significantly better adherence to their medications than those whose monthly earnings varied $(p=0.000)$. Subjects who had strong family support had significant good adherence to antihypertensive medication $(\mathrm{p}=0.000)$.

Table 4. Relationship between Family dynamics and Adherence

\begin{tabular}{|c|c|c|c|}
\hline Factors & $\begin{array}{c}\text { Good adherence } \\
\text { n }(\%)\end{array}$ & $\begin{array}{c}\text { poor adherence } \\
\text { n (\%) }\end{array}$ & $\begin{array}{r}\text { statistical } \\
\text { value }\end{array}$ \\
\hline \multicolumn{4}{|l|}{ Marital status $(N=420)$} \\
\hline single & $4(1.0)$ & $8(2.0)$ & \\
\hline Married & $126(30.0)$ & $164(39.0)$ & $\chi^{2}=10.6$ \\
\hline Widowed & $51(12.0)$ & $55(13.0)$ & $\mathrm{p}=0.031$ \\
\hline Separated & 0 & $8(2.0)$ & \\
\hline Divorced & 0 & $4(1.0)$ & \\
\hline \multicolumn{4}{|c|}{ Type of Marriage $(\mathrm{N}=408)$} \\
\hline Monogamy & $118(28.9)$ & $113(27.7)$ & $\chi^{2}=12.30$ \\
\hline Polygamy & $59(14.5)$ & $118(28.9)$ & $\mathrm{p}=0.000$ \\
\hline \multicolumn{4}{|l|}{ Family size $(N=420)$} \\
\hline $2-6$ members & $88(21.0)$ & $92(22.0)$ & $\chi^{2}=4.312$ \\
\hline$=7$ members & $93(22.0)$ & $147(35.0)$ & $p=0.04$ \\
\hline \multicolumn{4}{|c|}{ Family level income /month } \\
\hline \multicolumn{4}{|l|}{ (?) $(\mathrm{N}=420)$} \\
\hline$<18,000$ & $58(13.8)$ & $87(20.7)$ & $\chi^{2}=2.803$ \\
\hline$=18,000$ & $135(32.2)$ & $140(33.3)$ & $\mathrm{p}=0.09$ \\
\hline \multicolumn{4}{|l|}{$\begin{array}{l}\text { Family Support Rating } \\
\text { (PSS-Fa) }\end{array}$} \\
\hline Strong Family support & $156(37.0)$ & $126(30.0)$ & $\chi^{2}=52.30$ \\
\hline Weak family support & $25(6.0)$ & $113(27.0)$ & $p=0.000$ \\
\hline
\end{tabular}




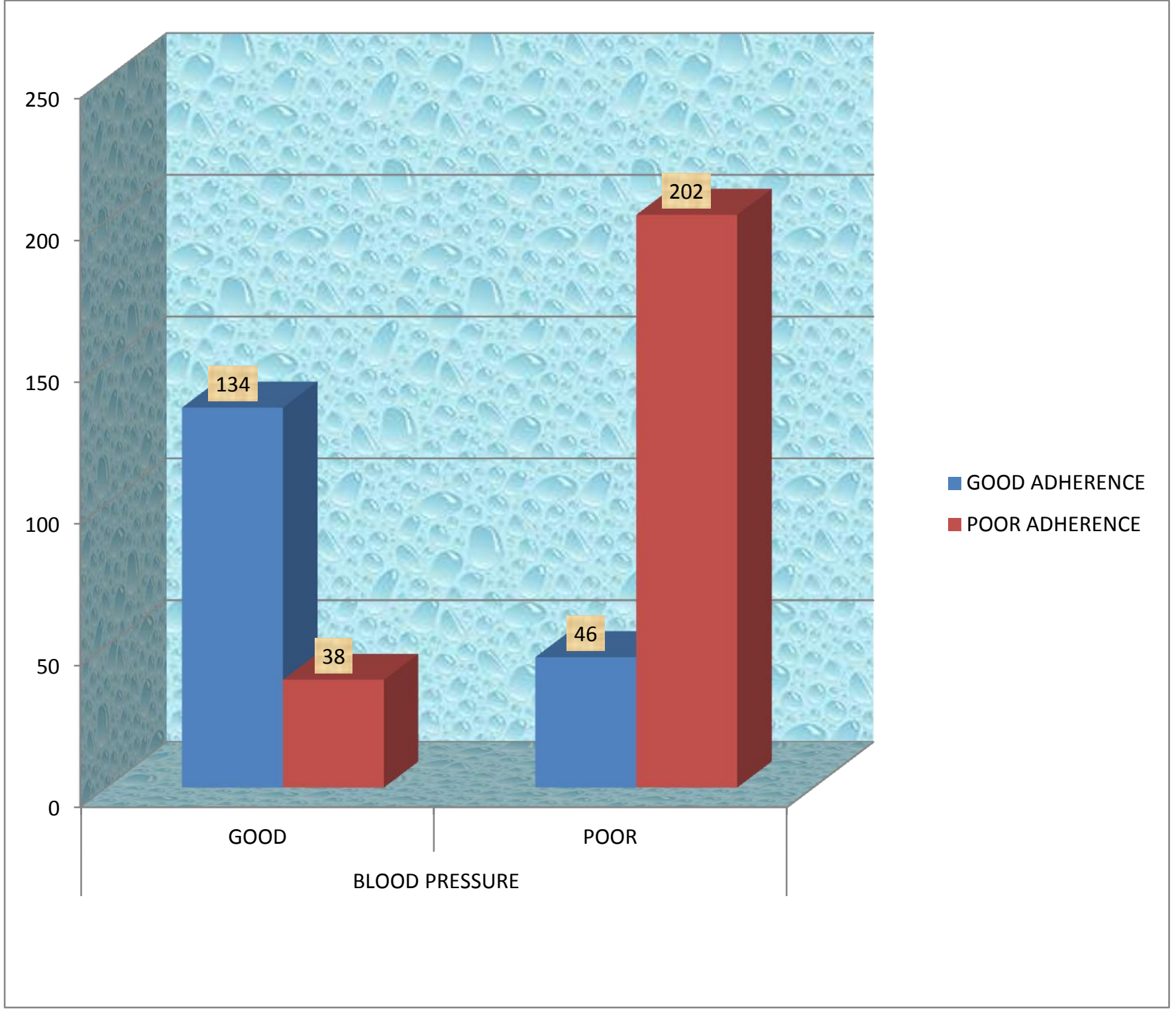

Fig 2: Blood pressure control and adherence to antihypertensive medications

Figure two shows that a total of $180(42.9 \%)$ participants had good adherence of which 134 (74.4\%) had good blood pressure control, while $240(57.1 \%)$ participants had poor adherence to medication of which 202(84.2\%) had poor blood pressure contol. The $\chi^{2}=146.12$, p-value $=0.000$. Odd ratio is 15.4 (CI of 9.5 to 25.1) with risk ratio of 4.2

\section{DISCUSSION}

The stress and socioeconomic implications of treating a complicated hypertension is enormous on the family. Most of the complications arise as a result of poor adherence to antihypertensive medication; adherence is usually a reflection of the family dynamics of the patient.
The mean age of the hypertensive patients in this study was $60.67^{ \pm} 13.85$ years. This is similar to mean age of $60.0^{ \pm} 12.0$ obtained in a communitybased study of the sociological aspects of hypertension in Idikan community. Idikan is located in the indigenous part of the city of Ibadan in the same south west Nigeria, it is a denselypopulated urban community within Ibadan city, with a population of 7,883 . ${ }^{12}$. However, this is higher than the mean age was $56.6 \pm 13.2$ years found in multicenter cross-sectional study where patients were recruited from four hospitals: Korle$\mathrm{Bu}$ Hospital, Ghana, and University of Port Harcourt Teaching Hospital, Apapa General Hospital Lagos, and University College Hospital Ibadan, Nigeria. ${ }^{8}$ The sites of their study are more 
urban and industrialised cities than Ido Ekiti where our study was carried out. Residents in rural and semi urban communities are less exposed to stress and pollutions which are known triggers of hypertension. Likewise, the mean age of the hypertensive patients in this study was similar when compared with what was reported among residents in USA 58.9 years ${ }^{16}$ This may also be explained by the westernized lifestyle Nigerians are currently adapting.

The age group distribution revealed a pattern of increasing numbers of subjects with age, with a maximum number $(29 \%)$ at age group 51-60 years. Almost three quarters, $(73.1 \%)$ of the subjects were over the age of 50years. This is consistent with the fact that the prevalence of hypertension increases with age in most populations, and the prevalence is highest in individuals over the age of fifty. $2,17,18$

In many populations, there is a higher prevalence of hypertension in females than in males. ${ }^{12}$ This was corroborated by a slight female predominance in this study (male: female $=1: 1.8$ ). The difference in sex ratio of hypertensive patients has been associated with the differences in the relative frequency of obesity and physical activity among the sexes. ${ }^{4,12}$ Nevertheless some studies reported higher prevalence of hypertension among male ${ }^{17}$, 19 , while some other studies could not find any difference in prevalence of hypertension between the two sexes. ${ }^{2,19}$

Majority of the participants had only primary education $(37.9 \%)$ and majority of them were in social class V $(49.0 \%)$, this may be a reflection of the location of the study centre. Similar report was given by a study done among hypertensive patients in a community setting in the southwest of Nigeria. $^{12}$

The level of adherence (43.1\%) recorded in this study is still unacceptably low. The level of good adherence found in this study is much lower than what was found in some parts of the country. Using the same methodology, a study done in the southeast Nigeria found good adherence in $70.7 \%$ of their respondents. ${ }^{19}$ The level of good adherence is generally low in different parts of developing countries. ${ }^{20}$ The same trend was seen in a multicenter study carried out in Nigeria and Ghana, where the combined level of adherence was found to be $33.3 \%$, though varied greatly among the studied Hospitals. ${ }^{8}$ The probable reasons for the low level of adherence in this study is the low level of family support and low level of education among the studied population .Educational background and family support have been reported as a very important factor in medication adherence. ${ }^{14}$

This study also shows that family dynamics (marital status, type of marriage, family size, family income and perceived family support) were significantly associated with adherence to antihypertensive drugs. Married subjects had statistically significant $(\mathrm{p}=0.031)$ good adherence compared to single, separated, divorced or widowed subjects. Subjects in monogamous marriage type were statistically ( $p<0.0001)$ more adherent than those in polygamous set up. Fifty percent $(50.0 \%)$ of the subjects with $2-6$ members in the family had statistically significant $(\mathrm{P}=0.016)$ good adherence as compared to zero percent of single(unmarried) and $38.8 \%$ of subjects with 7 or more members. Having small family size place less financial burden on the family income, hence fund will be available to take care of the sick in the family. These findings are consistent with reports of some other studies. $^{21,22}$ Government in the recent time advocates for small family size in the NHIS by registering only four children per person under the scheme. Many studies on factors associated with adherence focussed on patient-related factors, health system-related factors, provider-related factors and medication-related factors, only a very few looked at adherence in relation to the family dynamics of the patients. The family is the unit of care; it has great importance in effective management of diseases. It influences the causation of acute diseases and has a great impact on the rehabilitation of chronic disease patients. The family unit determines therapeutic success or 
failure (including medication adherence). ${ }^{10,}{ }^{11} \mathrm{In}$ Bangladesh and India, a study by WHO found that adherence was related to standard of living of people. ${ }^{23}$ When the family is not too large it is most likely the standard of living is good. A non significant association existed between family income and medication adherence $(\mathrm{p}=0.09)$ in this study. This may be as a result of the classification of monthly earning into more or less than $\$ 18,000.00$ of Nigeria minimum monthly wage. Where a wider range is used a probable significant association may be found like in many others studies where significant positive association was found between income and adherence to medications. ${ }^{19-23}$

There was a significant association between level of family support and medication adherence $(p<0.001)$. Majority of subjects with weak or no family support (81.9\%) had poor adherence, while $55.3 \%$ of subjects with good adherence had strong family support. The effects of family support on the maintenance and promotion of health of individuals may be the possible reason. In a study done in Rajshahi Medical College Hospital $(\mathrm{RMCH})$ and a private clinic in Rajshahi. ${ }^{24}$ Family support was associated with motivation on the part of the patient to take prescribed medicines and go to the physician. One-third were never asked by their family members to take medicines or visit their physician. Three-fifths had to depend on money from family for treatment. Eighty percent needed an accompanying person when seeking treatment. ${ }^{24}$

The contexts of people's lives determine their health, and so blaming individuals for having poor health or crediting them for good health is inappropriate. Individuals are unlikely to be able to directly control many of the determinants of health. These determinants or things that make people healthy or not include many factors of which family or social support is important. Social support networks inform of greater support from families, friends and communities is linked to better health. ${ }^{25-27}$
In conclusion, because barriers to medication adherence are complex and varied, solutions to improve adherence must be multifactorial, the finding from our study stresses the importance of functional family and strong family support as important factors influencing medication adherence among hypertensive patients.

We therefore recommended based on the outcome of this study that family dynamics should be thoroughly verified in each of physicians' consultation before prescribing medications so as to improve adherence to medications and each consultation should be used to advocate for strong family tie.

Limitation: the information on level of adherence was obtained through self-report and pill-count, it is therefore possible that there will be reporting bias. One limitation to calculating adherence using this method is that it assumes that the number of pills absent was actually taken by the patients. In addition, this method may not be representative of long-term adherence patterns because patients may exhibit white-coat adherence, or improved medication-taking behavior in the 5 days before health care encounter.

\section{Author Contribution}

Gabriel OE: Conception and Design, Interpreted and analyzed the data of the study

Ajetunmobi OA: Reviewed literature and wrote the discussion.

Shabi OM and Busari OA: Critically revised the article.

Adebara IO and Dada SA: Proof read the manuscript.

\section{REFERENCES}

1. WHO (2014) Global status report on non communicable diseases 2014 Geneva: World Health Organization.

2. Ekwunife OI, Aguwa CN. A meta analysis of prevalence rate of hypertension in Nigerian populations. Journal of Public Health and epidemiology. 2011 Dec 31;3(13):604-7. 
3. Chiazor IE, Oparah AC. Assessment of hypertension care in a Nigerian Hospital. Tropical Journal of Pharmaceutical Research. 2012 Feb 1;11(1):137-45.

4. Ambaw AD, Alemie GA, Mengesha ZB. Adherence to antihypertensive treatment and associated factors among patients on follow up at University of Gondar Hospital, Northwest Ethiopia. BMC public health. 2012 Apr 10;12(1):1.

5. Sheilini MM, George A, Pai MS, Sanatombi E. Antihypertensive treatment, medication Non- Adherence and factors leading to Non-Adherence among elderly. Medical Science. 2014 Aug; 3 (8).

6. Goyal R, Sarwate N. A correlative study of hypertension with lipid profile. Int J Res Appl Natural Soc Sci. 2014;2:143-50.

7. Ogah OS, Okpechi I, Chukwuonye II, Akinyemi JO, Onwubere BJ, Falase AO, Stewart S, Sliwa K. Blood pressure, prevalence of hypertension and hypertension related complications in Nigerian Africans: A review. World journal of cardiology. 2012 Dec 26;4(12):327.

8. Boima V, Ademola AD, Odusola AO, Agyekum F, Nwafor CE, Cole H, Salako BL, Ogedegbe G, Tayo BO. Factors Associated with Medication Nonadherence among Hypertensives in Ghana and Nigeria. International journal of hypertension. 2015 Oct 5;2015.

9. Busari OA, Olanrewaju TO, Desalu OO, Opadijo OG, Jimoh AK, Agboola SM, Busari OE, Olalekan O. Impact of patients' knowledge, attitude and practices on hypertension on compliance with antihypertensive drugs in a resource-poor setting. TAF Preventive Medicine Bulletin. 2010;9(2):87-92.

10. Campell TL, Bray JH. The family's influence on health. In: Rakel RE, editor. Text book of family practice. $6^{\text {th }}$ ed.
Philadelphia London. New york. WB Saunder 2001; 34-40.

11. Berge JM, Wall M, Larson N, Loth KA, Neumark-Sztainer D. Family functioning: associations with weight status, eating behaviors, and physical activity in adolescents. Journal of adolescent health. 2013 Mar 31;52(3):351-7.

12. Osamor PE, Owumi BE. Factors associated with treatment compliance in hypertension in southwest Nigeria. Journal of Health, Population and Nutrition. 2011 Dec 1:619-28.

13. Morisky DE, Ang A, Krousel-Wood M, Ward HJ. Predictive validity of a medication adherence measure in an outpatient setting. The Journal of Clinical Hypertension 2008 May 1;10(5):348-54.

14. Procidiano ME, Heller K. Measures of perceived social support from friends and family: Three validation studies. American Journal of Community Psychology 1983; 11: 1- 24.

15. Lam WY, Fresco P. Medication adherence measures: an overview. BioMed Res Int. 2015

Jan

$$
\text { 1;2015:217047. }
$$

16. Lee GK, Wang HH, Liu KQ, Cheung Y, Morisky DE, Wong MC. Determinants of medication adherence to antihypertensive medications among a Chinese population using Morisky Medication Adherence Scale. PloS one. 2013 Apr 25;8(4):e62775.

17. Egan BM, Zhao Y, Axon RN. US trends in prevalence, awareness, treatment, and control of hypertension, 1988-2008. Jama. 2010 May 26;303(20):2043-50.

18. Schiffrin EL. Hypertension: treatments, diabetes, and developing regions. The Lancet. 2012 Aug 11;380(9841):539-41.

19. Ikechuwku EO, Obinna UP, Ogochukwu AM. Predictors of Self Reported Adherence to Antihypertensive Drugs in a Nigerian Population. International Journal of Pharmaceutical Sciences. 2012;2:23-9. 
20. Ibrahim MM, Damasceno A. Hypertension in developing countries. The Lancet. 2012 Aug 17;380(9841):611-9.

21. Karaeren H, Yokuşoğlu M, Uzun S, Baysan O, Köz C, Kara B, et al. The effect of the content of the knowledge on adherence to medication in hypertensive patients. Ana do lu Kar di yol Derg. 2009;9(3):183-8.

22. Daniel AC, Veiga EV. Factors that interfere the medication compliance in hypertensive patients. Einstein (sao paulo). 2013 Sep;11(3):331-7.

23. Schroeder K, Fahey T, Ebrahim S. How can we improve adherence to blood pressure-lowering medication in ambulatory care? Systematic review of randomized controlled trials. Arch Intern Med. 2004; 164: 722-732.

24. Hussanin SM, Boonshuyar C, Ekram AR. Non-adherence to antihypertensive treatment in essential hypertensive patients in Rajshahi, Bangladesh. Anwer Khan Modern Medical College Journal. 2011;2(1):9-14.

25. Alsolami F, Hou XY, Correa-Velez I. Factors affecting antihypertensive treatment adherence: a Saudi Arabian perspective. Clinical Medicine and Diagnostics. 2012;2(4):27-32.

26. Afolabi BA, Afolabi MO, Afolabi AA, Odewale MA, Olowookere SA. Roles of family dynamics on adherence to highly active antiretroviral therapy among people living with HIV/AIDS at a tertiary hospital in Osogbo, south-west Nigeria. African health sciences. 2013 Dec 1;13(4):920-6.

27. Tabasi HK, Madarshahian F, Nikoo MK, Hassanabadi M, Mahmoudirad G. Impact of family support improvement behaviors on anti diabetic medication adherence and cognition in type 2 diabetic patients. Journal of Diabetes \& Metabolic Disorders. 2014 Nov 25;13(1):1. 